\title{
Experiências antropológicas e educativas com estudantes idosos
}

Elaine Lima Silva

lainelimao@gmail.com

\section{Resumo}

A antropologia procura mostrar que categorias e modos de ser que nos são familiares e que nos parecem naturais e evidentes são resultados de processos socioculturais e que seus significados diferem entre grupos sociais, sofrendo transformações ao longo do tempo. Este artigo esboça um breve estudo sobre essas modificações conceituais e sociais, com o objetivo de demonstrar as rupturas sofridas nos processos de envelhecimento, dado à variabilidade e heterogeneidade das relações familiares e dos modos de viver as velhices no ocidente. A metodologia utilizada foram as observações participantes e análises da experiência da autora enquanto professora de antropologia em um programa de universidade aberta para a terceira idade no primeiro semestre de 2012. Os resultados obtidos foram a percepção de como os 12 estudantes idosos experienciaram os conteúdos da disciplina a partir de suas próprias vivências e do processo de ensino-aprendizagem obtido a partir das sociabilidades e da solidariedade "no tecer junto" conforme Morin (1997).

Palavras-chave: Antropologia. Envelhecimento. Educação.

\section{Anthropological and educational experiences with elderly students}

\begin{abstract}
Anthropology aims to show that concepts and ways of being that are familiar to us and at first glance seem natural and obvious, in fact are result from a sociocultural process, and their meanings differs between social groups, being able to transformations over time.This article draws a brief study of these conceptual and social changes, in order to demonstrate the disruptions suffered in aging processes, since the variability and heterogeneity of family relationships and ways of living the old ages in Western society. The methodology used were participant observation and analysis of the author's experience as a professor of anthropology at the university open program to seniors in 2012.1.The results obtained were the perception of how twelve elderly students experienced the course content from their own experiences and the teaching-learning process obtained from the sociability and solidarity "to weave together" as Morin (1997).
\end{abstract}

Keywords: Anthropology. Aging. Education. 


\section{INTRODUÇÃO}

Beauvoir (1991) descreve como os chineses, judeus e os gregos tratavam seus velhos. Na China, Confúcio justificava moralmente a autoridade, associando a velhice à posse da sabedoria; a longevidade para os judeus era considerada como "suprema recompensa da virtude". As palavras gregas Géra e géron significam ao mesmo tempo idade avançada e o privilégio da ancianidade, de honra ligada à velhice, virtude im prescindível para o conselho de anciãos ligado ao rei na antiga Pólis (BEAUVOIR, 1991, p. 120). Cícero (2001) argumenta a respeito da vida ativa, indagando se a velhice é motivo de afastamento dos assuntos públicos, ao que ironicamente responde que um homem jovem e vigoroso não pode enfrentar sozinho, devendo valer-se da sabedoria dos mais velhos.

No ritual dos Kĩsêdjê ou Suyá, índios que habitam o Xingu do Mato Grosso no Brasil, os jovens iniciados são considerados como expressão máxima da ideia de masculinidade e autocontrole, enquanto o comportamento dos idosos é o oposto, caracterizado pelo humor, descontração e obscenidade. Os velhos da sociedade Kĩsêdjê possuem um papel social de atuar como palhaços nos rituais, responsáveis por eventuais cenas de humor ao final da tarde, quando provocam risadas nos mais jovens. Também a autoridade dos especialistas em rituais dos Suyá vem da sabedoria e memória para cantos (SEEGER, 2003).

Os exemplos dados pelos (as) autores (as) demonstram a heterogeneidade do envelhecimento e a ambiguidade no modo de tratamento das pessoas idosas. Magalhães (1989) considera que a homogeneidade nunca foi a característica da velhice, velhos sempre foram ricos e pobres, venerados ou denegridos e tratados tanto de forma dura quanto generosa pelas famílias e comunidades, não havendo necessariamente um padrão para isso. Ressalta que, em algumas sociedades, ditas tradicionais, atingidas por pragas e outras epidemias, era estimulado o gerontocídio.

Para Giddens (2000), foi no século XVIII que a maior parte das instituições modernas das sociedades ocidentais se consolidou, fazendo com que certos eventos e ações distantes atuassem de modo intenso e crescente sobre nossas vidas. Embora nas sociedades ditas pré-modernas e sociedades não ocidentais tivessem algum tipo de marcação etária como critério de diferença, é na modernidade que se dá relevância à institucionalização do curso da vida no mundo ocidental.

Segundo Àries (2006), desde a Idade Média até o século XVIII, um dos traços dominantes era a mistura de idades na organização social, embora o mesmo autor reconheça que, em épocas anteriores, nas áreas de civilização oral e rural, tem-se o registro de algumas sociedades organizadas por classes de idade, mas é, a partir do século XVII, se intensificando ao longo do século XVIII no mundo ocidental, que artistas começaram a representar crianças em suas obras, não mais como pequenos adultos ou como seres de estimação, ao mesmo tempo em que há um recolhimento da família nuclear - pai, mãe, filhos (as) - longe dos espaços públicos, mais preocupados com a proteção da família contra os intrusos, voltada para a intimidade e estabelecendo espaços individuais nos cômodos da casa.

A modernidade teria aumentado a distância entre adultos e crianças, não apenas por considerar a infância como uma fase de dependência, mas também pela construção do adulto como um ser independente, com maturidade psicológica e com direitos e deveres de cidadania. A mistura de idades, citada por Àries (2006), anterior a esse distanciamento etário regulamentado, permitia que crianças, adultos e velhos pudessem compartilhar dos mesmos espaços, inclusive aprender todos juntos, sem segmentações e comportamentos segregados.

De acordo com Hareven (1999), no final do século XIX, a criação da adolescência seguiu um processo semelhante, enquanto um estágio de vida reconhecido. Estilos de vida e certas congregações de jovens foram caracterizados como comportamento próprio de adolescente. O século XX designou o adolescente ou o jovem como seu herói, por sua força física e espontaneidade. Com o despontar de um crescimento acelerado da população idosa, especialmente na Europa, houve um maior interesse médico por essa faixa etária. No início do período da Revolução Industrial, autores (as) passaram a comparar o corpo a uma máquina sujeita ao desgaste, analogia já feita por René Descartes (1596-1650), associando o conceito de velho ao conceito de 
doença. Porém, análises da fisiologia do envelhecimento e implicações clínicas das alterações observadas contrariam a ideia de que o envelhecimento possa ser uma doença. O conceito de Gerontologia, de acordo com Neto (2006), surge em 1903 (do grego geronto: velho, ancião e logia, do grego logos: tratado, estudo a respeito de), utilizado pela primeira vez pelo cientista russo Elie Metchnikoff (1845-1916), como uma nova especialidade de estudo.

Magalhães (1989) sugere terceira idade como um termo associado ao período de formação, atividade produtiva e inatividade remunerada, respectivamente atribuída às crianças e jovens, adultos e velhos aposentados.

Após os anos 60 do século XX, o termo idoso (a) e terceira idade foram ganhando adeptos, uma vez que a questão do envelhecimento ter se constituído enquanto um "problema social” a ser resolvido, especialmente em torno das questões da previdência. No âmbito educacional, a partir do modelo da Université du Troisiéme Age (UTA) criada em 1973 na França, outras universidades abertas para a terceira idade se intensificaram, primeiramente na Europa, depois na América e num grande número de países, abrindo espaço também para a integração e pesquisas na área do estudo do processo de envelhecimento (CACHIONI, 2003).

A partir de 1980 essas universidades intensificaram em adaptar seu currículo na melhoria do processo de socialização, na educação permanente e nas oportunidades do exercício contínuo da cidadania. De acordo com a mesma autora, em 1983 surge no Brasil a primeira experiência de um programa educacional voltado para pessoas idosas nos moldes do contexto francês, o Núcleo de Estudos da Terceira Idade (NETI) na Universidade Federal de Santa Catarina em Florianópolis/SC. O NETI é o pioneiro em programas para pessoas idosas no Brasil, no caráter do ensino, pesquisa e extensão. As atividades desenvolvidas no núcleo pautam-se na elaboração, socialização e ampliação dos conhecimentos, estabelecendo o resgate do papel do (a) idoso (a) na sociedade brasileira. Seus projetos têm consonância com as diretrizes do Estatuto do Idoso (Lei Federal n. 10741/2003): "O idoso tem direito à educação, cultura, esporte, lazer, diversões, espetáculos, produtos e serviços que respeitem a peculiar condição etária”. Como missão o núcleo se propõe a redescobrir, recriar de forma integrada, sistematizar e socializar o conhecimento da Gerontologia, desenvolvendo atividades de ensino, pesquisa e extensão para inserir e promover as pessoas da terceira idade, no meio acadêmico e comunitário, como sujeitos em transformação e transformadores (NETI, 2013).

Dentre as 25 atividades oferecidas pelo NETI, é destacado, neste artigo, o Curso de Formação de Monitores da Ação Gerontológica (CFMAG), curso de extensão que atua desde o início, com o intuito de qualificar pessoas idosas em Gerontologia ao proporcionar o desenvolvimento de novos conhecimentos e ao estimular a prática do voluntariado na comunidade. A estrutura curricular do CFMAG compõe-se de 12 disciplinas distribuídas nas seguintes áreas de conhecimento: Ciências Humanas (Filosofia/30h, Psicologia/30h e Antropologia/30h), Ciências Sociais (Sociologia/30h, Gerontologia/30h, Ação Comunitária/30h, Metodologia da Ação Gerontológica/30h, Dinâmica de Grupo I/30h e II/30h e Supervisão de Estágio/90h), Ciências Jurídicas (Direito/30h) e Ciências da Saúde (Noções de Saúde/30h). O desenvolvimento de cada uma dessas disciplinas se desenrola ao longo de um semestre com uma carga horária total de 256 horas/ aulas ministradas em aulas teóricas e práticas, com encontros duas vezes por semana, das $14 \mathrm{~h}$ às $16 \mathrm{~h}$. $\mathrm{O}$ CFMAG envolve a participação aproximada de 180 estudantes idosos por semestre, ao mesmo tempo, tem sido campo de estágio e de bolsa para acadêmicos, além de ser espaço propício de trocas de saberes entre estudantes vinculados ao núcleo que queiram acompanhar as aulas e as atividades do curso.

Este artigo surge a partir das experiências da autora na disciplina de Antropologia do CFMAG junto à professora do Departamento de Antropologia da UFSC Vânia Zikán Cardoso, enquanto monitora voluntária da disciplina. A monitoria permitiu agregar saberes ligados à gerontologia, à antropologia e à própria vivência didática, um passo para que, em 2011, a autora deste assumisse a disciplina como professora voluntária. Este artigo aborda a experiência das atividades dessas aulas para uma turma de 12 estudantes idosos, sendo 10 mulheres e 2 homens no primeiro semestre de 2012. 


\section{Material e Métodos}

Os relatos dessas experiências se pautam no programa da disciplina, no caderno de atividades (diário de campo) utilizado para a elaboração das aulas, com anotações sobre as ações dos estudantes idosos e as observações sobre as ações deles; os trabalhos realizados a partir dos textos e das discussões em salas de aula, da construção do processo de ensino-aprendizagem que foi se dando nas interações, na "solidariedade do tecer junto", no dizer de Morin (1997).

Mesmo previamente planejado, o programa da disciplina foi apresentado para a turma, para possíveis sugestões/alterações, sendo aprovado pela maioria. A antropologia tem buscado mostrar que categorias e modos de ser que nos são familiares e que nos parecem naturais e evidentes, como, por exemplo, a família, o feminino, o masculino, o "velho", são resultados de processos socioculturais, e que seus significados diferem entre grupos sociais, sofrendo transformações ao longo do tempo. A reflexão buscou estimular um novo olhar sobre esses fenômenos sociais que fazem parte do nosso cotidiano, contribuindo, assim, para a compreensão da singularidade e complexidade dos processos de envelhecimento do ser humano. A metodologia pautou-se em aulas expositivas, diálogos, apresentação de trabalhos em grupo e individual e leitura dos textos. Como o curso não avalia através de notas, as avaliações tiveram como base a participação nas atividades em sala de aula, na leitura dos textos para que um diálogo pudesse se estabelecer, depoimentos orais e textos escritos. É sabido que nem todas as atividades propostas no planejamento aconteceram ou tiveram o êxito desejado, visto mudanças ocorridas no fluxo do decorrer das aulas.

Os conteúdos iniciaram pelas definições do que é a antropologia, apresentando as possíveis vertentes dos seus estudos: antropologia social, cultura, urbana, médica, do envelhecimento, entre outras. O texto de James Clifford sobre "A experiência etnográfica" (2002) contextualiza a legitimidade do antropólogo a partir do século XX a partir do "olhar treinado", ou seja, a capacidade de transgredir as rotineiras formas limitadas e normativas de olhar, diferente dos registros documentários dos séculos anteriores, realizados por viajantes, missionários e comerciantes, carregados muitas vezes com pré-conceitos, mas que têm seu valor histórico, pois são os únicos registros existentes. O texto de Ilka Boaventura Leite, "Produzir o texto, polir o olhar" (1998), aborda o papel da antropologia nos contextos atuais e destaca “o 'olhar antropológico' cultivado durante o século XX e que, segundo a autora, “[...] é um movimento contínuo de fazer e desfazer o eu e o outro, indo e vindo, deslocando-se na busca constante de uma posição que possibilite ampliar o olhar, ver o ainda não-visto" (BOAVENTURA LEITE, 1998).

O conceito de cultura é apresentado a partir do texto de Roque B. Laraia, "Cultura: um conceito antropológico" (2001), definindo as "diversas lentes" possíveis de perceber a cultura do outro a partir de sua própria, os comportamentos padrões, geralmente naturalizados como "corretos", possibilitando o surgimento de diversos pré-conceitos, etnocentrismos, xenofobias. As interferências culturais no campo biológico, por exemplo o caso do "banzo", apatia sofrida pelos africanos retirados de seu habitat, que levara muitos ao suicídio durante o período da escravização. Já nesse momento, os conceitos de velhice e envelhecimento puderam ser percebidos enquanto categorias sociais flexíveis de acordo com cada cultura.

$\mathrm{Na}$ terceira aula, o conceito de família pode ser visualizado pela ótica das gerações com o texto de Maria L. Rocha-Coutinho, "Transmissão geracional e família na contemporaneidade” (2006), que conceitua o termo enquanto instituição social mais antiga. A partir da pesquisa histórica, desde o Período Colonial até os dias atuais, a autora ressalta para a ampliação do conceito nas variadas formas de viver em família, cada vez mais um espaço de convivência entre várias gerações, partilhando, muitas vezes, os mesmos eventos. Esse conceito permitiu entrar no papel desempenhado pela pessoa idosa nas relações familiares, nos valores, hábitos, costumes e tradições transmitidos através das gerações nas sociedades ditas tradicionais e modernas.

O conceito de envelhecimento surge junto ao de família, com o texto de Clarice Peixoto, "Entre o estigma e a compaixão e os termos classificatórios velho, velhote, idoso, terceira idade" (2007), que aborda o histórico do envelhecimento desde o século XVI, inserindo o conceito nos modos capitalistas de produção, 
especialmente a partir do surgimento das cidades com o advento da Revolução Industrial, transformando as relações familiares de acordo com Marx e Engels em o Manifesto Comunista de 1848: “[...] a burguesia rasgou o véu de emoção e de sentimentalidade das relações familiares e reduziu-as a mera relação monetária" (MARX \& ENGELS, 2004). A modernidade, mais especificamente o capitalismo, foi capaz de segmentar as idades: primeira idade inativa (crianças), segunda idade ativa (adultos) e terceira idade (inativa), conceitos que não dão mais conta das heterogeneidades vividas pelas pessoas idosas ainda ativas em seus percursos rumo à quarta, quinta idade. O texto retrata ainda a velhice institucionalizada no Brasil, num primeiro momento devido à previdência, às políticas assistencialistas e, seguindo modelos europeus, às novas formas de gestar o envelhecimento pela ótica dos programas educacionais.

Visto que o NETI é majoritariamente frequentado por mulheres, tal como acontece em outros programas e atividades para a terceira idade, o conceito de gênero é explorado a partir do texto de Flávia Mattos Motta, "Velha é a vovozinha" (1998), uma pesquisa realizada em Porto Alegre/RS na extinta Legião Brasileira de Assistência (LBA). A autora privilegia a faceta "faceira" das informantes, entendida como forma particular da construção de uma identidade feminina que tenta escapar da passagem do conceito de "ser mulher sexuada" para "ser velha assexuada". Desse modo, Motta contraria o enfoque negativo da velhice, geralmente dado pela literatura ou o próprio discurso da decrepitude inerente às pessoas idosas, principalmente nas camadas mais populares. A pesquisa foi possível pela afinidade da autora com o grupo pesquisado, revelada pela sensibilidade em perceber aquelas mulheres, tal qual elas se percebiam e a percebiam, ou conforme sua citação: "O reconhecer-me nelas foi o que possibilitou a 'tradução' das suas experiências, mas foi o reconhecer-se em mim que criou intimidade e confiança” (MOTTA, 1998, p. 38). Nesse texto, foi possível transitar pela(s) sexualidade(s), tema que geralmente é considerado um tabu, mas durante o debate nas aulas não sofreu nenhuma resistência por parte dos estudantes.

\section{RESULTADOS E ANÁLISE}

Sem saber quem eram propriamente as pessoas presentes na aula e o que poderiam saber e esperar sobre a disciplina, inicialmente foi distribuído uma folha para que respondessem: "O que sei/não sei sobre antropologia" e "O que espero da disciplina". Seguem alguns comentários, sem portanto mencionar seus autores, para preservar suas identidades: 1)"Acho que é algo relacionado à cultura. Quero muito aprender e entender o que realmente é"; 2) É o estudo profundo de todas as espécies: ser humano, animal e vegetal, para que possamos ter conhecimento do tempo da vida"; 3) "Acredito que a antropologia é uma forma de reunir variáveis do estilo de vida do homem, maneiras de se comunicar, de viver, se relacionar. Espero adquirir novos conhecimentos"; 4) "Não sei qual é a definição, mas imagino o estudo do ser humano, seu comportamento como um todo no meio em que ele vive"; 5) "É o estudo dos usos e costumes do ser humano"; 6) "Estudo do comportamento dos seres vivos, desde o seu nascimento até a sua morte, isto é, como nasceram, onde e como viveram e o que nos assemelha a eles. Espero conseguir aprender a conhecer a caminhada de nossos antepassados com o olho no futuro"; 7) "Não sei ao certo, mas estou com a mente aberta para assimilar tudo o que for transmitido e espero que tenhamos uma bela troca de sabedoria didática com a nossa experiência de vida, pois, quem vive muito, e não só passou pela vida, aprendeu muito no seu dia a dia";8) "Eu espero que ela tenha o propósito de nos auxiliar na função para a qual nos formaremos, que é de cuidadores".

Como se pode perceber, há suposições bem aproximadas do que é antropologia, presentes no imaginário do que ouviram, leram, aprenderam em outras situações, além de mostrarem-se abertos às possibilidades de novos conhecimentos. Após as primeiras explanações em sala de aula com base nos textos, foram debatidas as respostas, e alguns estudantes se mostraram interessados e, na próxima aula, levaram para a sala textos antropológicos encontrados em revistas, jornais sobre diversos assuntos como as terras indígenas.

$\mathrm{Na}$ aula seguinte, com o propósito de iniciar o conceito de família, foi pedido aos estudantes para que 
levassem fotos familiares e compartilhassem com os demais suas histórias. Foi possível perceber a diversidade e variedade dos modos de viver em família. Alguns trouxeram fotos de seus pais falecidos, irmãos, outros somente da família nuclear: ela/ele, esposo/esposa e filhos (as), outros ainda dos animais de estimação, das noras e genros, filhos (as) do primeiro casamento de seus cônjuges, entre outras. Essa atividade foi realizada em duas aulas, visto que a riqueza das histórias suscitadas pelas fotos, as experiências compartilhadas possibilitadas pela proximidade geracional entre os estudantes, advindos de contextos diferenciados, mas se (re)descobrindo no outro, ou, conforme Rocha-Coutinho (2006): "Geração é um grupo de pessoas com idades semelhantes que vivenciaram uma problemática histórica concreta de experiências comuns como o sistema político, social, econômico e cultural”. (BENINCÁ; GOMES apud ROCHA-COUTINHO, 2006, p. 97-98). Os relatos e discursos sobre as fotos foram os mais diversos: 1) "Quando casei fiquei mais próxima com a família do marido"; 2) "Já casei com tudo pronto/antes de casar namorei todo o alfabeto de A a Z"; 3) "Eu já fiz parte de várias famílias: eu, meu pai e madrasta. Quando casei, quando separei, quando meu filho casou e saiu de casa diminuiu, mas depois aumentou com os netos. Fins de semana a família é outra, todos se encontram"; 3) "Não queria casar de noiva, nem com pompa, mas o marido queria e ele que casou todo de branco".

Rupturas já puderam ser percebidas nos rompimentos com categorias sociais engessadas, geralmente presentes no imaginário do senso comum que homogeiniza essas categorias, determinando um só tipo de comportamento que seria/deveria ser seguido por todas as pessoas, especialmente as idosas, ou seja, nem todas as mulheres dessa geração casaram virgens ou com o primeiro namorado, além do que, há outras interpretações do que se considera família, não só a nuclear: pai, mãe, filhos(as). As formas variadas de constituição das relações familiares e seus membros são, se utilizando de Boaventura Leite (1998), um “[...] movimento contínuo de fazer e desfazer o eu e o outro, indo e vindo [...]”, tal como é apontado por elas: "Eu já fiz parte de várias famílias [...], ou seja, o conceito de família, bem como o de cultura ou do que é ser "mulher", "homem", "velho" ou "velha" são construções sociais flexíveis, plásticas, moldadas de acordo com os contextos, tempo e lugar.

A partir das discussões dos textos durante as aulas e das reflexões suscitadas, grupos de estudantes - alguns optaram fazer o trabalho sozinhos - escolheram temáticas pertinentes à antropologia e ao processo de envelhecimento para desenvolverem o trabalho final. Não houve direcionamento por parte da professora sobre as escolhas das temáticas e, como alguns estudantes escolheram entrevistas como recursos metodológicos, um resumo do texto de Briggs (1986), "Learning how to ask", foi distribuído aos estudantes com algumas sugestões: "[...] o uso da entrevista como ferramenta que parte sempre de um objetivo e de uma metodologia escolhida pelo (a) pesquisador (a). Este (a) impõe uma visão sua, entendida como o direcionamento dado pelo (a) entrevistador (a) à entrevista" (BRIGGS, 1986). Dessa forma, os estudantes perceberam que as entrevistas que seriam realizadas por eles dependeriam não somente das respostas de seus entrevistados, mas de toda a (inter)relação criada, do "clima" estabelecido, do recorte dado. As propostas foram as mais diversas tanto no conteúdo quanto na forma, desenvolvidas mais ou menos dentro do prazo de um mês e meio e apresentadas nas duas últimas aulas. Seguem algumas das temáticas escolhidas e alguns dos resultados:

- Grupo 1: pesquisa com uma senhora octogenária, tia de uma das estudantes. Segundo o grupo, a escolha se deu pelas facilidades de acesso e de tempo, visto que a aluna é vizinha e cuidadora dessa senhora. A metodologia utilizada foi a observação participante e entrevistas semiabertas, apresentando depoimentos e exposições fotográficas da entrevistada, demonstrando um envelhecer otimista, seu apego com bonecas e os trabalhos como rendeira;

- Grupo 2: entrevistas com pessoas idosas aleatórias em lugares diversos, como ponto de ônibus, sobre a experiência de envelhecer. A metodologia utilizada foram entrevistas estruturadas, e a apresentação na aula se deu através da exposições de imagens das pessoas e seus depoimentos. As imagens foram previamente consentidas pelas pessoas entrevistadas, através de um Termo de Consentimento disponibilizado pela professora ao grupo. Alguns dos resultados apresentados foi o descontentamento das pessoas idosas 


\section{Extensio $\mid$ Relato de Experiência}

em relação às políticas públicas;

- Grupo 3: análise de personagens idosos da novela global "Avenida Brasil”: Muricy (Eliane Giardinin), Mãe Lucinda (Vera Holtz), Nilo (José de Alencar) e Leleco (Marcos Caruso). Especialmente neste último, o debate teve grande participação, devido ao personagem ter um corpo atlético, se relacionar com uma moça bem mais jovem e depois voltar com sua ex-esposa da mesma idade. Alguns dos resultados apresentados pelo grupo foram as mudanças percebidas que ocorreram ao longo do tempo nas imagens divulgadas pela mídia da pessoa idosa, geralmente retratada tal qual a "Dona Benta" do Sítio do Pica-Pau Amarelo;

- Grupo 4: pesquisa na Revista Galileu, edição de fevereiro de 2011, no artigo "A Cura do Envelhecimento". Abordaram a busca histórica da humanidade pela Fonte da Juventude com o objetivo da imortalidade. Em nosso século, cientistas perpetuam essa busca, na tentativa de prolongar a vida ao máximo e até mesmo evitar para sempre a morte. Isso inclui o combate às piores doenças sofridas, como o câncer. O grupo apontou, porém, o perigo do uso da palavra "cura", que só corrobora com os pré-conceitos sobre a velhice e o envelhecimento;

- Estudante 1: observação e análise do seu histórico familiar a partir da geração das mulheres de sua família. A opção foi por não gostar de entrevistar ninguém, "até porque já tem muito velho em casa". Ressalta que teve boas experiências com os velhos e velhas de sua família, espelhando seu próprio relacionamento com o marido no casamento de sua tia, que ela considerava perfeito;

- Estudante 2: observação geracional dos homens da família (avô-pai) e de suas próprias experiências a respeito do trabalho. A metodologia utilizada foi a observação participante, a análise de documentos e fotos familiares pertinentes aos percursos geracionais dos homens no mundo do trabalho. A apresentação foi oral;

- Estudante 3: a partir da experiência de uma viagem à Portugal, aluna contextualiza, a partir de fotos, os modos de viver das pessoas naquele país, traçando um breve paralelo com os modos de viver as velhices no Brasil;

- Estudante 4: a pesquisa foi realizada na internet, no blog "Mais de 50" para interessados em namoros, viagens, criação de blogs, postagem de fotos ou, segundo a aluna, "um mundo de possibilidades dentro da internet, já que é viúva”. Os resultados obtidos foram a percepção de que, entre os usuários do blog, há uma difícil aceitação da velhice e algumas observações sobre as dificuldades e facilidades das pessoas idosas com a "era da computação".

A maioria das apresentações foram embasadas nos textos discorridos durante o curso, nos debates, nas próprias experiências de envelhecer dos estudantes, nas trocas de saberes entre eles e a professora, nos processos de ensino-aprendizagem. O clima foi de descontração, havendo enorme expectativa para apresentarem seus trabalhos. Para fins de planejar melhor a apresentação, os estudantes se organizaram em dois grandes grupos que incluíam as apresentações dos grupos e das pessoas individuais em um mesmo espaço, cada um falando sobre sua parte. Dois grandes cartazes foram confeccionados para dar conta da produção de todos, conforme as Ilustrações 1 e 2 . 
llustração 1 - Apresentação do trabalho final

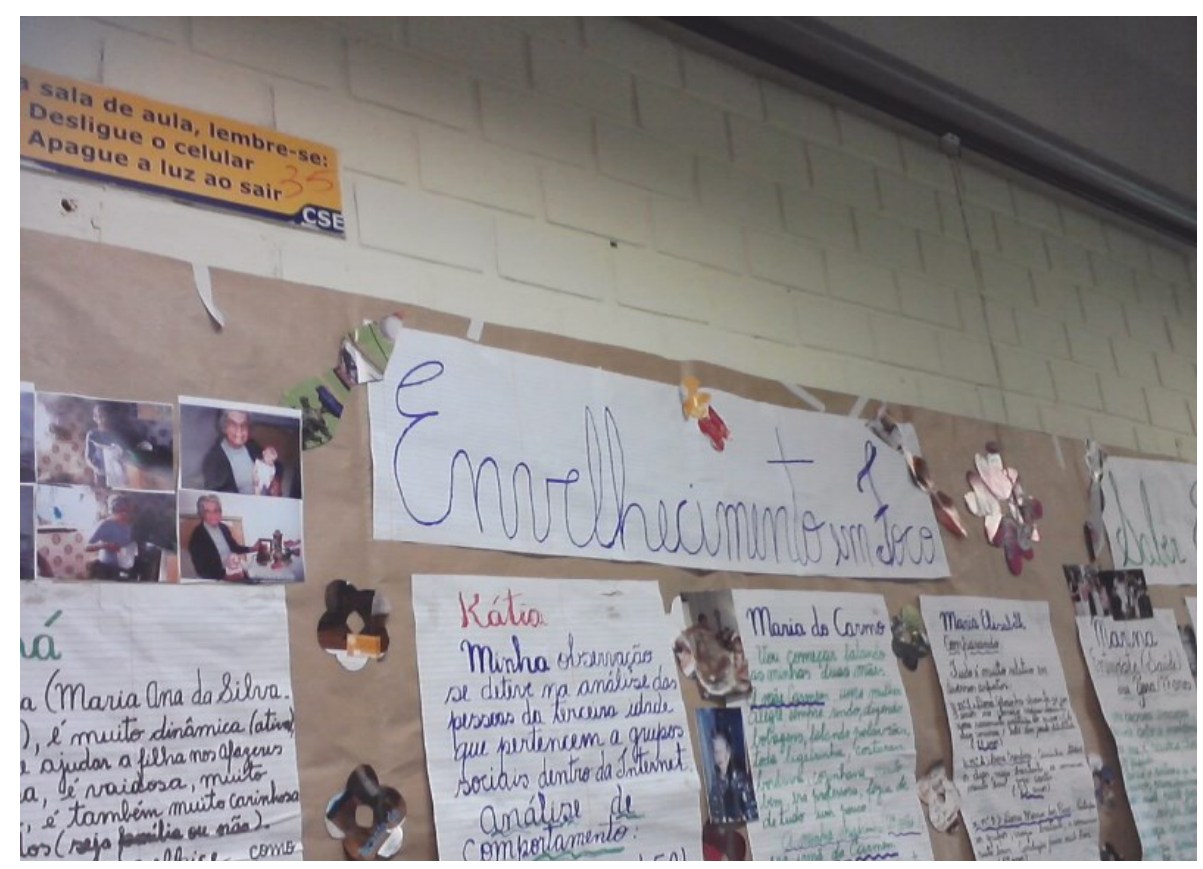

Fonte: Arquivos pessoais da autora (2012)

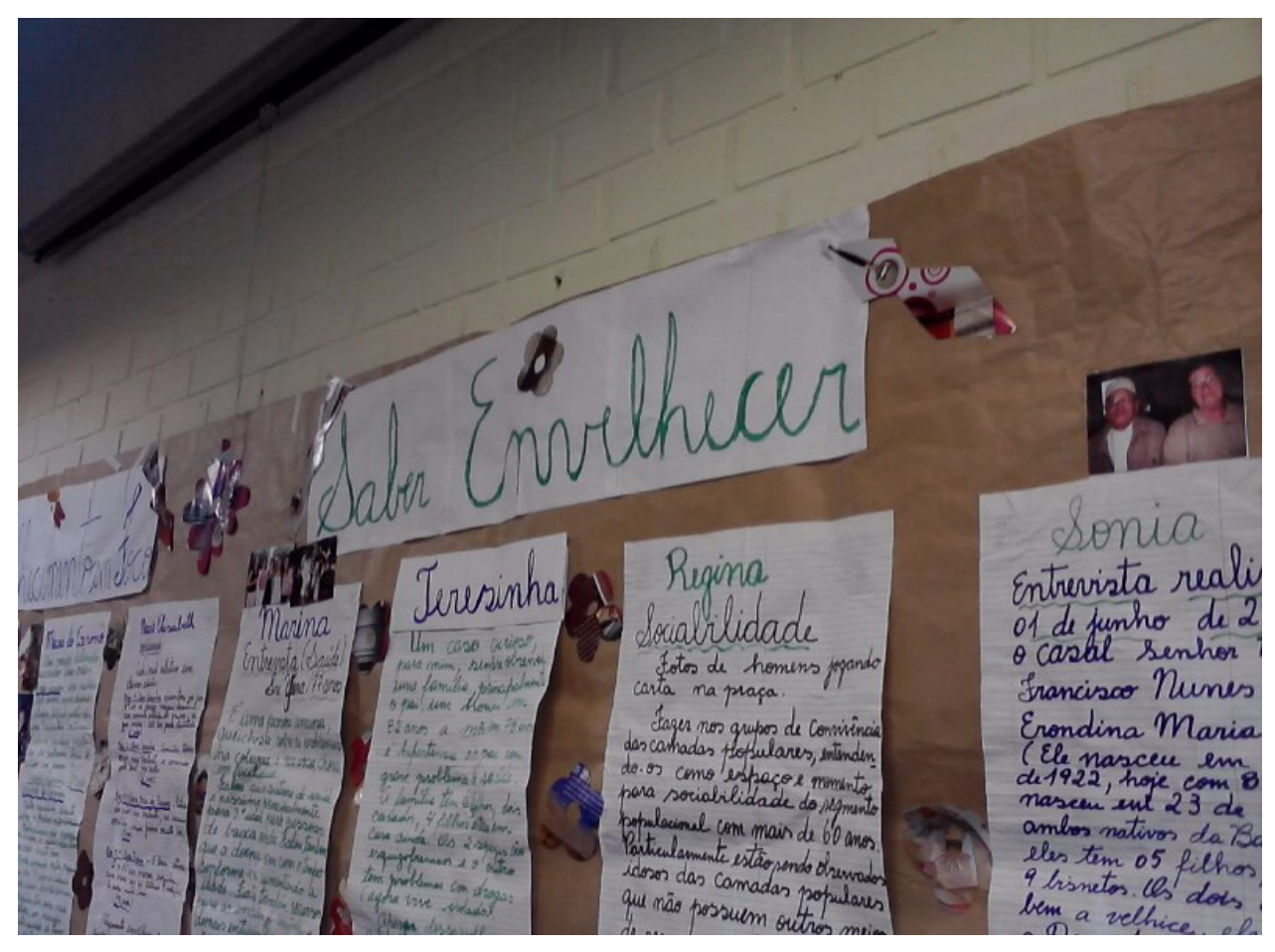

Ilustração 2 - Apresentação do trabalho final II

Fonte: Arquivos pessoais da autora (2012) 


\section{Extensio $\mid$ Relato de Experiência}

\section{Considerações Finais}

Considerando o processo educativo como "[...] uma teia educacional que aumenta a oportunidade de cada um transformar todo instante de sua vida num instante de aprendizado, de participação e de cuidado" (ILLICH, 1973), o cenário do processo de ensino-aprendizagem durante as aulas foi de cuidado de "todos para com todos". Durante o período, um dos alunos, esposo de uma das alunas, ficou doente e faltou algumas aulas. Na sua ausência e no seu retorno, houve muitas manifestações de carinho e apoio, e sua permanência se estendeu até hoje, quando a turma está quase se formando. As sociabilidades foram espontâneas, nenhum grupo foi definido pela professora, mas eles próprios se reuniam, incluindo, alternando as pessoas entre os grupos. Os estudantes puderam reconhecer sua capacidade de continuar apreendendo na convivência com o outro e pelo outro, independente de qualquer segmentação de idade, classe ou gênero. Para os dois homens, permanecer em uma sala com "tantas mulheres juntas" pareceu não ser um impedimento para suas participações. Mesmo se sabendo que não há como pensar educação de adultos e idosos, sem pensar nos itinerários históricos diferenciados de homens e mulheres, ou entre o "espaço público" (trabalho) e o "espaço privado" (doméstico), respectivamente, durante as aulas, tais diferenciações foram atenuadas pela avidez no apreender, pela busca incessante do saber, especialmente porque esses binômios não correspondiam à realidade da turma, muitas alunas durante suas vidas ocuparam muito mais os espaços públicos do que os domésticos.

Nos relatos e trabalhos produzidos pelos estudantes, foi possível perceber a desnaturalização de conceitos engessados, do "olhar ampliado" para outras formas familiares, que não a nuclear, de rompimentos de regras e normativas, uma inversão de papéis, percebidas, por exemplo, na aluna que preferia não casar com "pompa" e sim o marido que casou de branco, ou no casamento "tardio" da "namoradeira", que casou aos 44 anos com o marido que lhe deu os filhos que ela não quis ter.

Nesse sentido, de acordo com Debert (2004), as fronteiras etárias sempre foram muito tênues, é preciso levar em conta as variações nas etapas e na extensão em que o curso de vida é periodizado em sociedades modernas distintas, e a experiência de diferentes grupos sociais numa mesma sociedade; e a experiência, conforme Bondía (2002), é o que nos passa, o que nos acontece, o que nos toca. Não o que se passa, não o que acontece, ou o que toca. A disciplina de antropologia no CFMAG, ao que parece, permitiu aos estudantes experienciarem a partir do que lhes fazia sentido, do que os tocara. O texto de Rocha-Coutinho (2006) sobre famílias e gerações, por exemplo, foi percebido/sentido a partir das próprias vivências dos alunos e alunas em seus discursos e histórias familiares na atividade das fotos. Apesar de alguns estudantes informarem não saber o que seria antropologia, se identificaram de imediato em alguns debates, nas pesquisas realizadas com seus pares geracionais, pertencentes a contextos diferentes, mas partilhando alguns eventos similares no campo social, cultural e político, permitindo se perceberem como parte "de um mesmo mundo". O aprendizado se deu no grupo, nas trocas solidárias, nos trabalhos realizados nos fins de semana e intervalos, nos cafés após as aulas. Motta (1998) reconheceu, em sua pesquisa com as idosas da LBA, que "O reconhecer-me nelas foi o que possibilitou a 'tradução' das suas experiências, mas foi o reconhecer-se em mim que criou intimidade e confiança". Assim foi com as relações entre os estudantes e a professora, esta sendo mulher "mais jovem" pode se encontrar neles, identificando-se como parte de uma "comunidade de destino", conforme Bosi (1987). Identificando-se na professora, eles ultrapassaram o binômio ou a hierarquia professora-estudantes, perceberam-se colegas, confidentes, estudantes universitárias, sujeitos do aprender. Nos diálogos, os pronomes de tratamento "senhor" ou "senhora" deram lugar aos seus nomes de batismo, seus apelidos, àqueles mesmos usados por seus familiares ou como eram chamados(as) desde crianças. 


\section{REFERÊNCIAS}

ÀRIES, Philippe. História social da criança e da família. Trad. Dora Flaksman. $2^{\text {a }}$ Ed. Rio de Janeiro: LTC, 2006.

BEAUVOIR, Simone. A Velhice. Rio de Janeiro: Nova Fronteira, 1991.

BOAVENTURA, L. Ilka (org.). Produzir o texto, polir o olhar. In: Ética e Estética na Antropologia. Florianópolis: UFSC. Programa de Pós-Graduação em Antropologia Social, 1998.

BONDÍA, L. Jorge. Notas sobre a experiência e o saber de experiência. In: Revista Brasileira de Educação. São Paulo/SP: Univ. Estadual de Campinas. 2002.

BRIGGS, C. Learning how to ask. Cambridge: Cambridge University Press, 1986.

BOSI, Ecléa. Memória e Sociedade: lembranças de velhos. 2a ed. SP: T.A. Queiroz: Universidade de São Paulo, 1987.

CACHIONI, Meire. Quem educa os idosos? Um estudo sobre profesores de universidades da terceira idade. Campinas/SP: Ed. Alínea, 2003.

CÍCERO, Marco Túlio. Saber envelhecer. Porto Alegre: L\&PM, 2001.

CLIFFORD, James. A experiência etnográfica: antropologia e literatura no século XX. Rio de Janeiro: Editora UFRJ, 2002

DEBERT, G. Guita. A Reinvenção da Velhice: socialização e processos de reprivatização do enve-h lhecimento. São Paulo: Fapesp, 2004.

ESTATUTO DO IDOSO. Senadora Ideli Salvatti. Brasília, 2003.

GIDDENS, Anthony.; PIERSON, Christopher. Conversas com Anthony Giddens: o sentido da mo- dernidade. Trad. Luiz Alberto Monjardim. Rio de Janeiro: FGV, 2000.

HAREVEN, K. Tâmara. Novas imagens do envelhecimento e a construção social do curso da vida. In: Cadernos Pagu: Gênero em gerações. Org. Guita Grin Debert. Campinas/SP: Núcleo de Estudos de Gênero/ UNICAMP, 1999.

ILLICH, Ivan. Sociedade sem escolas. Petrópolis: Vozes, 1973.

LARAIA, B. Roque. Cultura: um conceito antropológico. 14a edição. Rio de Janeiro: Jorge Zahar Editor, 2001.

MAGAlHÃES, N. Dirceu. A Invenção Social da Velhice. RJ: edit. Papagaio, 1989.

MARX, Karl; ENGELS, Friedrich. Manifesto do Partido Comunista 1848. Trad. Sueli Tomazzini B. Cassal. Porto Alegre: L\&PM, 2001. 
MORIN, Edgar. Complexidade e ética da solidariedade. In: Ensaios de Complexidade. Coord. Gustavo de Castro [et al]. Porto Alegre: Sulina, 1997.

MOTTA, M. Flávia. Velha é a vovozinha: identidade feminina na velhice. Santa Cruz do Sul: EDUNISC, 1998.

NETO, Matheus P. O Estudo da Velhice: histórico, definição do campo e termos básicos. In: Tratado de geriatria e gerontologia. 2 ed. Rio de Janeiro: Guanabara- Koogan, 2006.

PEIXOTO, C. Entre o estigma e a compaixão e os termos classificatórios: velho, velhote, idoso, terceira idade ...In:Velhice ou Terceira Idade? 4ªed. São Paulo: FGV 2007.

ROCHA-COUTINHO, L. Maria. Transmissão geracional e família na contemporaneidade. In: BARROS, L. Myriam (org.). Família e Gerações. Rio de Janeiro: FGV, 2006.

SEEGER, Anthony. Povos indígenas no Brasil: sociedade e rituais. 2003. Disponível em: <http://pib.socioambiental.org/pt/povo/kisedje/1226>. Acesso em 10 janeiro 2013.

UNIVERSIDADE FEDERAL DE SANTA CATARINA. Núcleo de Estudos da Terceira Idade. Disponível em: <http://www.neti.ufsc.br/>. Acesso em: 11 jun. 2013. 